\title{
BiblioCom: estendendo o acervo de bibliotecas por meio de uma rede social para empréstimo de livros de acervos pessoais
}

BiblioCom: extending the collection of libraries through a social network to loan books of personal collections

\author{
Jordan Paulesky Juliani \\ Professor do Programa de Pós-graduação em Gestão da Informação - UDESC \\ E-mail: jordanjuliani@gmail.com
}

Divino Ignácio Ribeiro Junior

Professor do Programa de Pós-graduação em Gestão da Informação - UDESC

E-mail: divinoirj@gmail.com

Orlando Vieira de Castro Junior

Mestre em Controladoria pela Universidade Federal do Ceará - UFC Mestrando em Gestão da Informação - UDESC

E-mail: orlandovcj@gmail.com

Salete Teresinha Pompermaier Mestranda do Programa de Pós-Graduação em Gestão da Informação - UDESC Assistente Social da Universidade do Estado de Santa Catarina - UDESC E-mail: salete.udesc@yahoo.com.br

\author{
Francisco Rosa \\ Mestrando em Gestão da Informação - UDESC \\ E-mail: frchico.adm@gmail.com
}

\section{Resumo}

Trata-se de um estudo de caso cujo objetivo foi o desenvolvimento de um protótipo de rede social destinada ao empréstimo de livros entre os usuários da biblioteca universitária da Udesc, estendendo, dessa forma, o acervo da biblioteca com os acervos pessoais dos usuários da rede. $\mathrm{O}$ artigo registra um breve histórico das redes sociais na internet, pontuando a importância das novas tecnologias e como estas tem afetado a forma como buscamos informações nos dias atuais. Trata-se de uma pesquisa descritiva que usou como estratégia o estudo de caso. Como unidade-caso foi apresentado um protótipo de rede social destinada ao compartilhamento de livros e informações correlatas entre os usuários da biblioteca universitária da Udesc (Biblioteca Central da Udesc). São apresentados métodos de avaliação de usabilidade de sistemas baseados na web. A partir desses critérios, avaliou-se duas alternativas de plataformas para a criação de um protótipo de aplicativo que possibilitasse a criação de uma rede social onde cada usuário pudesse disponibilizar seus livros e/ou buscar livros a serem emprestados por outros usuários. Concluiu-se que o protótipo atendeu aos requisitos operacionais propostos e que poderia ser utilizado por bibliotecas para expandir seus acervos e como alternativa de interação com usuários.

Palavras-chave: Redes sociais. Bibliotecas. Programas de computador. Usabilidade.

\begin{abstract}
It is a case study whose objective was the development of a prototype social network for the loan of books among users of Udesc's university library, thus extending the collection of the library with the personal collections of users of the network. The article records a brief history of social networks on the Internet, highlighting the importance of new technologies and how these have affected the way we seek information today. It is a descriptive research that used case study as strategy. As a case-study unit, a social network prototype was presented for books sharing and related information among users of Udesc's University Library (Udesc Central Library). Usability evaluation methods are presented. Based on these criteria, we evaluated two alternative platforms for creating an application prototype that would allow the creation of a social network where each user could make their books available and/or search for books to be borrowed by other users. It was concluded that the prototype met the proposed operational requirements and could be used by libraries to expand their collections and as an alternative of interaction with users.
\end{abstract}

Keywords: Social networks. Libraries. Computer programs. Usability.

InCID: R. Ci. Inf. e Doc., Ribeirão Preto, v. 8, n. 2, p. 124-143, set. 2017/fev. 2018.

DOI: 10.11606/issn.2178-2075.v8i2p124-143 


\section{Introdução}

empréstimo de livros de acervos pessoais

Lubisco (2001, p. 95) aponta que os principais problemas de uma biblioteca universitária vão “desde a incompleteza das coleções de periódicos especializados e de referência, à falta de bibliografias básicas para o ensino de graduação e de pós-graduação, e à ociosidade das coleções". Tal situação é especialmente preocupante quando se considera o papel da biblioteca universitária como elemento integrante, fundamental ou mesmo imanente aos programas de ensino (LUBISCO, 2001, p. 88).

Nesse mesmo sentido, Machado e Blattmann (2011) demonstraram os resultados de uma pesquisa onde compararam as bibliografias básicas de 45 planos de ensino de uma universidade localizada no estado de Santa Catarina com a disponibilidade das obras citadas nas bibliografias em sua biblioteca. As autoras concluíram que as obras mais citadas nos planos de ensino são exatamente aquelas para as quais a biblioteca universitária não consegue atender a demanda dos alunos. Tal situação indesejável é ainda mais presente nas bibliotecas das universidades públicas, onde a falta de recursos orçamentários dificulta a renovação e atualização do acervo.

Entretanto, a condição das bibliotecas universitárias descrita por Lubisco (2001) e Machado e Blattmann (2011) pode ser modificada em tempos de economia compartilhada. Mendes e Ceroy (2015) lembram que

da natureza humana compartilhar bens e serviços. Qualquer pessoa, em algum
momento da sua vida, já emprestou livros, CDs, carro, bicicleta, DVDs, etc.
Entretanto, este comportamento individual de compartilhar coisas nunca teve o
condão de alterar a economia. Faltava escala e as transações se restringiam a amigos,
vizinhos e familiares.

O desenvolvimento tecnológico, especialmente o desenvolvimento de plataformas de software baseado na internet e dispositivos móveis, permitiu com que pudéssemos compartilhar bens e serviços de modo a criar um novo sistema sócio econômico denominado de economia compartilhada ou consumo compartilhado. Botsman e Rogers (2011) definem a economia compartilhada como um conjunto de práticas comerciais que não necessariamente envolvem a aquisição do produto ou qualquer tipo de troca monetária entre as partes envolvidas na transação. Essas práticas concentram-se no empréstimo, aluguel, trocas, doações, escambo e compartilhamento de bens e serviços.

Por seu turno, as mídias sociais têm se tornado cada vez mais um espaço onde as pessoas, além da troca de mensagens e notícias, podem negociar (vender, trocar e comprar) 
produtos e serviços. Redes sociais como o Facebook disponibilizam ferramentas simples que permitem a criação de lojas virtuais. Torna-se notório que a cada minuto surgem novas formas de utilizar a ligação de dados e novos serviços que a Internet cria para facilitar e melhorar a nossa experiência em alguma área.

Diante dessa nova realidade, surge a questão: seria possível a utilização dessas tecnologias de informação e comunicação com vistas à criação de uma rede social, congregando leitores, pesquisadores e estudantes, que disponibilizassem/compartilhassem seus acervos pessoais estendendo, dessa forma, o acervo de uma biblioteca universitária?

O presente estudo tem por objetivo propor a criação de uma rede social destinada a mediar o compartilhamento, na forma de empréstimo, de livros pertencentes aos acervos pessoais dos usuários de uma biblioteca universitária. Para atingir este objetivo, inicialmente são apresentados conceitos relacionados as redes sociais na Internet e a sua relação com a biblioteca, uma breve introdução a economia compartilhada e finalmente são descritos o métodos de avaliação de usabilidade de redes sociais a partir das suas interfaces. Em seguida são apresentadas as duas tecnologias experimentadas para a implementação da rede social proposta: a criação de comunidades no Facebook e a criação de um sítio na Internet por meio do framework visual para criação de aplicativos Bubble. As principais vantagens e desvantagens das duas alternativas foram avaliadas com base nas dez heurísticas propostas por Jakob Nielsen (1995). Por fim, apresenta-se um protótipo de um aplicativo para a criação de uma rede social vinculada a uma biblioteca universitária, detalhando seu funcionamento.

\section{Fundamentação Teórica}

2.1.As redes sociais virtuais na Internet e a biblioteca

Rheingold (apud IVAR-SOUZA, 2014) foi um dos primeiros autores a utilizar o termo "comunidade virtual" para definir um grupo de pessoas unidas em grupos de discussões que possuem um sentimento de vínculo social. À época, entre meados dos anos 1980 e início dos anos 1990, o autor se utilizava de instrumentos como "bulletin-board systems" (BBS) e salas de "Internet Relay Chat" (IRC) para manter de uma rede de relacionamentos sociais no ciberespaço. 
Com o passar dos anos, as empresas passaram a utilizar a Internet para se comunicar com potenciais clientes, fornecer informações sobre a empresa, promover ações de marketing e vender serviços e produtos por meio de suas páginas. Entretanto, no Brasil, até o final dos anos 1990, não havia muita interação com os então chamados "navegantes" nessas páginas. Soares e Hoppen (1998) realizaram uma análise dos sítios na Internet de 327 empresas que figuram na lista das 500 maiores e melhores empresas da revista Exame de 1997. Como resultado, os autores verificaram que apenas 101 das empresas listadas pela revista possuíam sítios na Internet. A maioria não possuía qualquer estrutura de interação ou coleta de dados dos navegantes.

Essa situação vem mudando deste os anos 2000, em especial com o surgimento das redes sociais virtuais, quando a interação com os usuários passou a ser uma tônica no relacionamento entre empresas e consumidores por meio da Internet. Marteleto (2001, p. 72) define uma rede social como "[...] um conjunto de participantes autônomos, unindo ideias e recursos em torno de valores e interesses compartilhados". Assim, as redes sociais virtuais são uma representação, no mundo virtual, de redes sociais similares às existentes em qualquer sociedade. De fato, a autora frisa que a participação das pessoas em redes sempre existiu na história da humanidade.

Redes sociais virtuais como o Facebook possuem ferramentas que permitem empresas de todo porte estabelecerem relações comerciais por meio da Internet. É possível criar páginas para comunidades que tenham o objetivo de vender, trocar ou anunciar produtos e serviços para públicos específicos e bem definidos. Tomaél, Alcará e Di Chiara (2005, p. 102) acrescentam que, "dependendo dos interesses que movimentam as interações na rede, esta pode ser seccionada em grupos que geralmente são profícuos para a própria rede, isto por mobilizarem atores que estejam envolvidos com uma temática específica”.

Diante do exposto, as redes sociais com temas específicos tendem a mobilizar mais fortemente os interagentes que possuem interesses comuns em um tema como, por exemplo, uma rede social dedicada ao empréstimo de livros e discussões sobre assuntos a eles relacionados.

A aplicação de novas tecnologias de informação e comunicação em bibliotecas, em especial nas bibliotecas públicas e universitárias, tem sido objeto de discussão em todo o mundo. O New Media Consortium publicou, em 2014, o Horizon Report (JOHNSON et al., 
2014) abordando as principais tendências, os desafios mais significativos e as tecnologias emergentes ao redor do mundo, bem como os impactos nas bibliotecas acadêmicas e de pesquisa decorrentes dessas tecnologias.

Segundo os autores, com o aumento de conteúdo disponível na Internet, as bibliotecas deixaram de ser a única fonte confiável de conhecimento. Essa mudança impactou não somente na forma como as pessoas buscam informações, mas também onde elas conduzem as pesquisas (JOHNSON et al., 2014). Ambientes online como Google Scholar e o Web of Knowledge selecionam e organizam dados de múltiplas fontes e se tornaram alternativas às pesquisas realizadas no ambiente da biblioteca.

Assim como as pesquisas acadêmicas expandiram suas possíveis fontes de informações, a partir da biblioteca física, incluindo fontes de informação na Internet, os vínculos entre os pesquisadores também se estenderam ao ambiente virtual. Portais como o Academia.edu, Mendeley, ResearchGate, Zotero e Scholastica oferecem, além do compartilhamento de publicações científicas, informações, contatos dos pesquisadores, ferramentas úteis como, por exemplo, gerenciamento de referências e atualização de currículos online (SZKOLAR, 2012).

Dessa forma, uma rede social na Internet que tenha como objetivo congregar uma comunidade de usuários de bibliotecas físicas teria, como potencial benefício, a expansão dos serviços da biblioteca servindo de espaço de interação entre os usuários, permitindo que estes se ajudem mutuamente a atender necessidades de informação eventualmente não supridas pela biblioteca física, por meio de um sistema de disponibilização e empréstimo de livros pertencentes aos próprios integrantes da rede social.

\subsection{Economia compartilhada}

Algumas das maiores empresas mundiais atualmente não possuem, e nem entregam, produtos e serviços. O que temos é um crescimento da economia compartilhada em escala global (ENTREPENEUR, 2011). Botsman e Rogers (2011) definem economia compartilhada como "[...] a troca, empréstimo, intercâmbio, aluguel e doação, reinventados por meio da tecnologia de rede em uma escala [...]". Segundo estes autores, o surgimento dessa economia está baseado em fatores econômicos, sociais e tecnológicos. Os sociais estão associados às preocupações crescentes com a sustentabilidade e meio-ambiente. Os econômicos relacionados 
a possibilidade de monetização do excesso e da ociosidade dos estoques individuais. Por fim os tecnológicos que permitiram a disseminação de redes sociais e a redução dos custos das transações pela eliminação dos intermediadores.

Gansky (2011) explica que essa economia compartilhada vem ganhando corpo, e se destacando, por apresentar a jovens empreendedores (e a empresas estabelecidas) ótimas oportunidades de negócio. Um dos modelos de negócio mais conhecidos da economia compartilhada é o serviço de transporte UBER, que permite com que os proprietários de automóveis possam oferecer uma "carona remunerada". Outro exemplo não menos expressivo é a plataforma de aluguel AIRBNB que possibilita, por exemplo, que uma casa de veraneio, poucas vezes utilizada por seus proprietários, possa ser ocupada por inquilinos durante o ano todo.

O compartilhamento de bens, a economia compartilhada, permite que não haja a necessidade de compra de produtos por múltiplos usuários, possibilitando uma troca entre eles. Gansky (2011) fala que existem cinco pontos chaves para esse tipo de consumo colaborativo ter se desenvolvido na sociedade:

a) A crise econômica, que gerou desconfiança sobre empresas antigas;

b) Ainda fruto da crise, as pessoas começaram a repensar o que era valioso para elas;

c) Com as mudanças climáticas no mundo, muitos produtos tiveram aumento em seus custos, consequentemente aumento no preço de venda;

d) Com o aumento exponencial da população, e a urbanização, surge um ambiente propicio para negócios colaborativos;

e) E por fim a evolução da tecnologia, que favorece, cada vez mais, negócios personalizados e customizados, atendendo a todo tipo de demanda.

2.3.Avaliação de usabilidade de redes sociais na Internet

Uma das questões relevantes no que diz respeito ao uso de redes sociais na Internet com vistas à criação e/ou manutenção de comunidades virtuais é a usabilidade de suas interfaces. 
Uma rede social na Internet pode ser considerada uma aplicação baseada em Web e, dessa forma, interfaces sem problemas de usabilidade proporcionam um aumento da produtividade, tornam mais simples o aprendizado e reduzem as possibilidades de erros em sua operação (SOARES; VELOSO; MEALHA, 2012).

A norma brasileira ABNT NBR 9241-11 define usabilidade com sendo a "medida na qual um produto ser usado por usuários específicos para alcançar objetivos específicos com eficácia, eficiência e satisfação em um contexto específico de uso" (ASSOCIAÇÃO BRASILEIRA DE NORMAS TÉCNICAS, 2002, p. 3). Assim, a usabilidade é um atributo de qualidade de um produto passível de ser medido ou avaliado com base em critérios prédefinidos.

Os métodos de avaliação analíticos são aqueles em que avaliadores examinam aspectos da interface com o usuário em termos de usabilidade (PRATES; BARBOSA, 2003). Tais avaliações têm por finalidade identificar problemas de usabilidade existentes em projetos de interfaces com vistas a propor melhorias.

Dentre os métodos de avaliação analíticos, destaca-se o método de avaliação heurística que tem como característica principal a utilização de critérios baseados em um conjunto de princípios ou diretrizes chamados "heurísticas" (NIELSEN, 1995). Tais heurísticas são baseadas nas melhores práticas e definidas por especialistas em interação homem-computador (IMC).

Shneiderman e Plaisant (2004), com base em suas experiências de mais de duas décadas, enumeraram oito princípios, chamados "regras de ouro", aplicáveis à maioria dos sistemas interativos:

a) Mantenha a consistência - para situações similares, espera-se que sequências de procedimentos sejam semelhantes. Figuras devem ter o mesmo significado nos diferentes locais onde forem utilizados. Deve-se buscar a consistência de terminologias.

b) Atenda à diversidade de usuários - Ao mesmo tempo em que a interface deve ser acessível para os novos usuários, deve-se ofereça atalhos aos usuários experientes.

c) Ofereça feedbacks informativos - para cada ação do usuário deve corresponder uma resposta do sistema. 

empréstimo de livros de acervos pessoais

d) Apresente as etapas do processo - Sequências de ações devem ser organizadas em grupos com início, meio e fim. O feedback de cada etapa dá ao usuário a sensação de satisfação pela conclusão da etapa e o prepara para o passo seguinte.

e) Ofereça uma forma simples de correção de erros - A interface deve prevenir erros. Nos casos em que o usuário cometa algum erro, o sistema deve fornecer orientações claras sobre a forma de corrigi-lo.

f) Permita fácil reversão de ações - Saber que eventuais erros podem ser desfeitos tranquiliza o usuário.

g) O controle do sistema é do usuário - Operadores experientes desejam sentir que estão no comando da interface e que esta responde às suas ações.

h) Evite sobrecarregar a memória do usuário: A interface deve ser simples e fácil de memorizar.

Nielsen (2012), por sua vez, definiu usabilidade como um atributo de qualidade que avalia o grau de facilidade de uso de uma interface pelo usuário. A palavra "usabilidade" também se refere aos métodos para melhorar a facilidade de uso durante o processo de projeto da interface com o usuário. $\mathrm{O}$ autor propõe cinco componentes de qualidade que definem a usabilidade de uma interface:

a) Facilidade de aprendizado: é fácil para os usuários concluírem tarefas básicas na primeira vez que eles usam a interface?

b) Eficiência: Uma vez que os usuários apreenderam a usar a interface, eles conseguem executar tarefas rapidamente?

c) Memorabilidade (Memorability): Quando os usuários voltam a usar a interface depois de um período sem usá-la, eles conseguem reestabelecer a proficiência no uso rapidamente?

d) Prevenção de erros: Quantos erros os usuários cometem? São erros graves? Eles conseguem corrigir os erros rapidamente?

e) Satisfação: O uso da interface é agradável? 
Para Nielsen (1993, p. 24, Tradução nossa), a usabilidade deve ser "parte de um sistema de aceitabilidade como critério para decidir se um sistema é bom o suficiente para satisfazer todas as necessidades e requisitos dos usuários e outros potenciais stakeholders". A aceitabilidade de um sistema, de acordo com o autor, é determinada pela sua aceitabilidade prática e aceitabilidade social. Ou seja, além de ser avaliado como aceitável com base nos critérios de usabilidade, o sistema deve ser socialmente aceitável a partir da percepção de sua relevância para uma comunidade de usuários.

Como critérios para avaliação de usabilidade, Nielsen (1995) ampliou os princípios propostos por Shneiderman e Plaisant, definindo dez heurísticas para a avaliação de usabilidade:

a) Visibilidade do status do sistema: o sistema deve sempre manter os usuários informados sobre o que está acontecendo por meio de feedback em tempo razoável.

b) Relação entre o sistema e o mundo real: o sistema deve falar a língua dos usuários, com palavras, frases e conceitos que lhes sejam familiares de modo a tornar a linguagem mais natural e lógica.

c) Controle e liberdade do usuário: deixar claro para o usuário a "saída de emergência" para o caso de escolhas erradas. Possibilitar refazer ou desfazer tarefas facilmente.

d) Consistência e padronização: o usuário não deve ter que adivinhar quando palavras diferentes, situações ou ações significam a mesma coisa. É preciso estabelecer as convenções da plataforma.

e) Prevenção de erros: deve-se tentar prever as situações em que os usuários podem cometer erros e solicitar confirmações antes de executar as ações.

f) É mais fácil reconhecer do que ter que lembrar: minimize o uso da memória do usuário tornando os objetos, ações e opções visíveis, assim ele não vai precisar ter que se lembrar de informações de uma parte do diálogo para outra.

g) Flexibilidade e eficiência no uso: atalhos, pouco vistos ou utilizados por usuários inexperientes, podem acelerar a interação para usuários experientes de modo que o sistema possa atender tanto a usuários experientes como inexperientes. 
h) Projeto estético e minimalista: os diálogos não devem possuir informações irrelevantes ou raramente usadas.

i) Ajudar o usuário a reconhecer, diagnosticar e corrigir erros: mensagens de erro devem ser expressas em linguagem clara (sem códigos), indicando precisamente o problema e sugerindo uma solução.

j) Ajuda e documentação: mesmo que seja melhor que o sistema possa ser usado sem documentação, pode ser necessário fornecer ajuda e documentação. Qualquer informação deve ser fácil de pesquisar, focada na tarefa do usuário, listar os passos concretos a serem dados, e não ser muito grande.

A avaliação de usabilidade se reveste de importância, pois, é esse atributo de qualidade que vai garantir, em última instância, que os interagentes de um aplicativo, página Web ou rede social consigam executar corretamente as tarefas necessárias para alcançar seus objetivos e satisfazer suas necessidades de informação.

\section{Procedimentos Metodológicos}

O presente estudo é uma pesquisa descritiva (LAKATOS; MARCONI, 2002) que usou como estratégia o estudo de caso (CALAZANS, 2007). De fato, a estrutura da pesquisa encontra consonância com o postulado por Lakatos e Marconi (2002, p.20), que afirmam que uma pesquisa descritiva deve abordar a "descrição, registro, análise e interpretação de fenômenos atuais".

Quanto ao delineamento da pesquisa, de acordo com Yin (2001), trata-se de um estudo de caso uma vez que, de modo a avaliar as opções tecnológicas para a criação do protótipo de rede social, serão analisados segundo critérios quali-quantitativos. Como unidade-caso será apresentado um protótipo de rede social destinada ao compartilhamento de livros e informações correlatas entre os usuários da biblioteca universitária da Udesc (Biblioteca Central da Udesc).

Os autores buscaram diferentes opções de tecnologias de informação e comunicação que permitissem a implementação de uma rede social capaz de congregar usuários que tenham os seguintes objetivos: 
a) Disponibilizar livros de sua propriedade para empréstimo a outros interagentes da rede social, estendendo o acervo da Biblioteca da Udesc;

b) Buscar e tomar de empréstimos livros que não estejam disponíveis na biblioteca da Udesc ou qualquer outra biblioteca institucional.

Como opções tecnológicas os autores avaliaram a utilização do Facebook como ferramenta para criação de uma comunidade naquela rede social, e o desenvolvimento de uma página própria na Internet com o uso do framework visual para criação de aplicativos Bubble. A rede social criada foi chamada provisoriamente de BiblioCom, numa alusão ao termo "Biblioteca Compartilhada".

Uma vez desenvolvidas as duas alternativas de protótipos, os autores avaliaram os aspectos positivos e negativos relacionados à usabilidade de cada uma das plataformas de implantação da rede social BiblioCom a partir das dez heurísticas propostas por Nielsen (1995).

\section{Resultados e Discussão}

A criação da uma comunidade virtual dedicada à troca e empréstimos de livros entre seus interagentes tem como finalidade congregar leitores e usuários da biblioteca física, expandido o ambiente de interação para a Internet.

Este espaço virtual, provisoriamente denominado BiblioCom, deve possuir as seguintes funcionalidades:

a) Autenticação do usuário no sistema a partir do seu cadastro na base de dados do sistema de gestão de acervo da Biblioteca da Udesc;

b) Cadastro dos livros disponibilizados pelos usuários para empréstimos;

c) Integração com a base de dados do sistema de gestão de acervo da Biblioteca da Udesc, permitindo a consulta ao acervo tanto da Udesc quanto dos acervos pessoais dos usuários da rede social;

d) Possibilidades aos usuários para acrescentarem informações adicionais sobre os livros cadastrados, tais como resenhas, avaliações, comentários e imagens;

e) Mecanismos de busca capaz de apresentar os livros disponíveis para empréstimo; 
f) Controle que permita ao usuário que emprestou um livro saber quem o tomou emprestado;

g) Mecanismo de rating para avaliação da confiabilidade dos usuários, tanto dos que emprestam como dos que tomam livros emprestados;

h) Possibilidades de interação entre os usuários por meio de linha do tempo e mensagens diretas;

Com vistas ao atendimento desses requisitos de operação, foram avaliadas duas possíveis plataformas para a criação de uma rede social na Internet que permitisse a manutenção da comunidade virtual dedicada à troca e empréstimos de livros: o Facebook, e o desenvolvimento de uma página Web por meio do Framework visual para criação de aplicativos Bubble. A seguir são apresentados os resultados das avaliações de usabilidade dos dois protótipos desenvolvidos em cada uma das opções tecnológicas.

\subsection{Criação de uma comunidade virtual no Facebook}

O Facebook permite a criação de comunidades virtuais por meio da opção de menu "Criar Grupo". A partir de um tutorial, o usuário que está criando o grupo deve informar o objetivo do grupo, que pode ser "Conectar e compartilhar", "Ser produtivo" ou "Compra e venda". Não há um tipo de grupo que tenha como objetivo emprestar ou trocar objetos. Dessa forma, optou-se pelo grupo "Compra e venda" por ser o que mais se assemelha ao objetivo pretendido, e pelo fato de ser o único tipo de grupo que permite a inclusão de itens a serem anunciados.

No que diz respeito às funcionalidades, o grupo criado no Facebook atende a maioria dos requisitos pretendidos a exceção dos itens "e" e "f". De fato, a plataforma não permite um controle eficiente de quem tomou livros emprestados, nem possibilita avaliar a confiabilidade dos usuários da comunidade.

Por se tratar de uma adaptação no uso de um grupo criado com objetivo de compra e venda de itens, o grupo BiblioCom no Facebook trata cada livro disponibilizado para empréstimo como um produto a ser vendido que deve ser cadastrado com preço zero. Tal situação, aliada a ausência de controle nos empréstimos, pode causar confusão nos usuários com relação aos reais propósitos do grupo. 
Como pontos que merecem destaque nessa opção tecnológica podem ser citados a rapidez e baixo custo de implementação, a facilidade no cadastro dos usuários e a popularidade da plataforma que dispensaria maiores investimentos em divulgação, além da pouca necessidade de aprendizado no uso do ambiente.

Com base nas dez heurísticas propostas por Nielsen (1995), podemos avaliar a usabilidade do grupo BiblioCom no Facebook, conforme tabela a seguir:

Quadro 2 - Avaliação da usabilidade do grupo BiblioCom criado por meio do Facebook

\begin{tabular}{|c|c|c|c|}
\hline Heurística & Atende & $\begin{array}{c}\text { Não } \\
\text { Atende }\end{array}$ & Observações \\
\hline Visibilidade do status do sistema & $\mathrm{X}$ & & Mensagens de status do próprio Facebook. \\
\hline Relação entre o sistema e o mundo real & & $\mathrm{X}$ & $\begin{array}{l}\text { O grupo usa a lógica de compra e venda e } \\
\text { não de empréstimo. Tal adaptação pode } \\
\text { causar confusão nos usuários. }\end{array}$ \\
\hline Controle e liberdade do usuário & $\mathrm{X}$ & & $\begin{array}{l}\text { Há possibilidade de editar publicações e } \\
\text { excluí-las em caso de erros. }\end{array}$ \\
\hline Consistência e padronização & $\mathrm{X}$ & & Segue o padrão de utilização do Facebook. \\
\hline Prevenção de erros & & $\mathrm{X}$ & $\begin{array}{l}\text { Não há previsões específicas para situações } \\
\text { de possíveis erros relacionados ao objetivo } \\
\text { do grupo (empréstimo de livros). }\end{array}$ \\
\hline $\begin{array}{l}\text { É mais fácil reconhecer do que ter que } \\
\text { lembrar }\end{array}$ & $\mathrm{X}$ & & $\begin{array}{l}\text { Os diálogos são padronizados e obedecem } \\
\text { à lógica de funcionamento do Faceboook. }\end{array}$ \\
\hline Flexibilidade e eficiência no uso & & $\mathrm{X}$ & $\begin{array}{l}\text { Foi necessário adaptar o grupo destinado a } \\
\text { compra e venda para um fim diferente do } \\
\text { planejado. Entretanto a interface do } \\
\text { Facebook não possibilita ou não apresenta } \\
\text { alterações que permitam alterar os termos } \\
\text { "compra" e "venda" para "empréstimo" e } \\
\text { "devolução" }\end{array}$ \\
\hline Projeto estético e minimalista & & $\mathrm{X}$ & $\begin{array}{l}\text { Interface do Facebook possui informações } \\
\text { em demasia tais como publicidade, lista de } \\
\text { contatos do usuário, menu lateral com } \\
\text { grande quantidade de opções. Apenas a } \\
\text { segunda coluna da página diz respeito } \\
\text { diretamente ao grupo BiblioCom. }\end{array}$ \\
\hline $\begin{array}{l}\text { Ajudar o usuário a reconhecer, } \\
\text { diagnosticar e corrigir erros }\end{array}$ & & $\mathrm{X}$ & $\begin{array}{l}\text { As mensagens de erro são destinadas aos } \\
\text { erros relacionadas à utilização normal do } \\
\text { Facebook, e não podem ser adaptadas para }\end{array}$ \\
\hline
\end{tabular}



empréstimo de livros de acervos pessoais

\begin{tabular}{l|c|c|l}
\hline Heurística & Atende & $\begin{array}{c}\text { Não } \\
\text { Atende }\end{array}$ & \multicolumn{1}{|c}{ Observações } \\
\hline & & & $\begin{array}{l}\text { tratar eventuais erros específicos na } \\
\text { interação com o grupo BliblioCom. }\end{array}$ \\
\hline Ajuda e documentação & X & $\begin{array}{l}\text { A ajuda e documentação não pode ser } \\
\text { adaptada para esclarecer situações } \\
\text { particulares da interação com o grupo } \\
\text { BiblioCom. }\end{array}$ \\
\hline
\end{tabular}

Fonte: Elaborado pelos autores a partir de Nielsen (1995).

Verifica-se que a utilização do Facebook, como alternativa tecnológica para implementação da comunidade virtual BiblioCom, somente atende a quatro das dez heurísticas propostas por Neilsen. Tal situação decorre, essencialmente, do fato de que o grupo assim criado teve que ser adequado a um tipo-padrão de grupo disponibilizado pelo Facebook, que não pode ser personalizado para atender às necessidades específicas de funcionamento da comunidade virtual dedicada ao empréstimo de livros.

4.2. Utilização do framework visual Bubble para criação da rede social BiblioCom na Internet

A segunda opção tecnológica implementada como protótipo foi a criação de uma página Web com a utilização do Framework visual Bubble. Esta alternativa permite uma maior personalização da interação com os usuários além de uma interface mais minimalista e intuitiva.

A rede social BiblioCom implementada sobre esta plataforma permitiu o atendimento dos requisitos planejados para o sistema. O framewor kBubble é uma ferramenta de programação visual em ambiente web por meio da qual é possível implementar aplicativos tanto para desktop como dispositivos móveis (celulares e tablets).

O desenvolvimento é feito sem necessidade de conhecimentos de linguagens de programação, arrastando-se com o mouse os componentes desejados. Assim, o aplicativo BiblioCom pode ser customizado para atender aos requisitos estabelecidos.

A figura a seguir ilustra a tela inicial do BiblioCom, a partir da qual o usuário pode adicionar livros disponíveis para empréstimo, e fazer buscas por livros que tem interesse de pedir emprestado a outros usuários. 


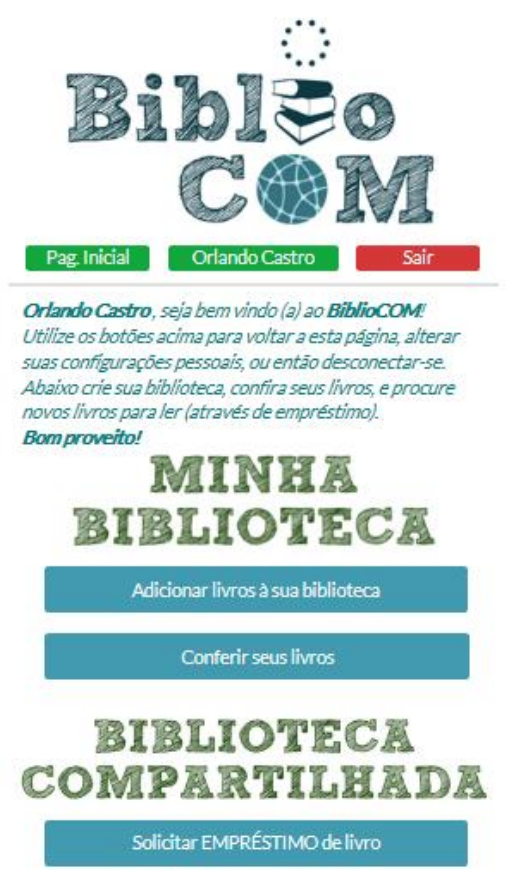

Figura 1 - Tela inicial do BiblioCom criado como página da Web Fonte: Elaborado pelos autores com uso do framework visual Bubble.

Quando o usuário solicita empréstimo de um livro, o sistema encaminha uma mensagem por e-mail ao proprietário do livro para que este entre em contato com o solicitante e combinem a melhor forma de entrega. O BiblioCom busca preservar a identidade dos usuários, por isso, apenas quando o proprietário do livro confirma a disponibilidade do livro para empréstimo, a pessoa que pediu emprestado receberá seus dados para contato.

A figura 2 ilustra a tela de busca do BiblioCom a partir da qual o usuário localiza os livros disponibilizados para empréstimos por todos os usuários da rede, na medida em que vai escrevendo o título do livro, nome do autor ou editora. 

BiblioCom: estendendo o acervo de bibliotecas por meio de uma rede social para empréstimo de livros de acervos pessoais

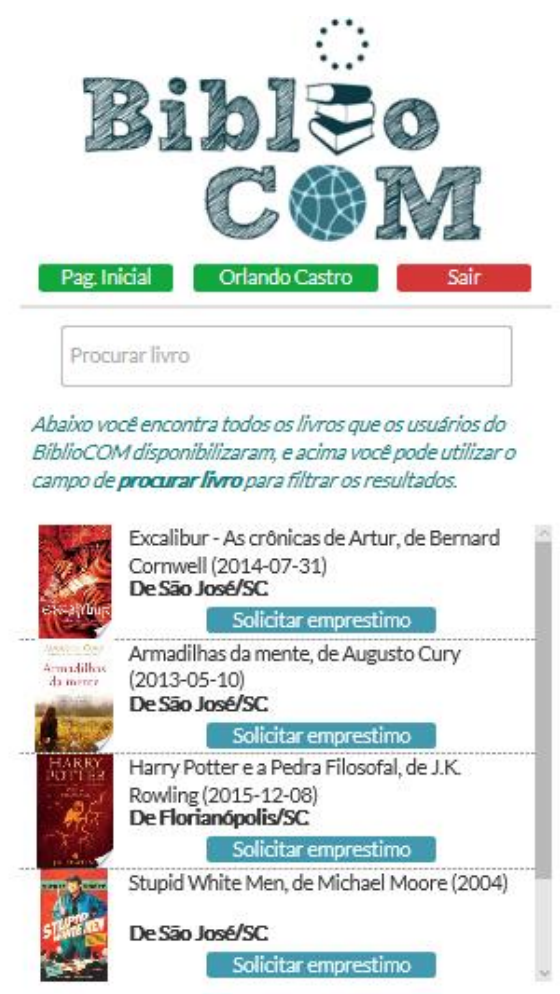

Figura 2 - Tela de busca do BiblioCom criado como página da Web Fonte: Elaborado pelos autores com uso do framework visual Bubble.

Com base nas dez heurísticas propostas por Nielsen (1995), podemos avaliar a usabilidade da página Web do grupo BiblioCom, conforme tabela a seguir: 
Jordan Paulesky Juliani, Divino Ignácio Ribeiro Junior, Orlando Vieira de Castro Junior, Salete Teresinha Pompermaier e Francisco Rosa BiblioCom: estendendo o acervo de bibliotecas por meio de uma rede social para empréstimo de livros de acervos pessoais

Quadro 3: Avaliação da usabilidade do grupo BiblioCom criado como página da Web

\begin{tabular}{|c|c|c|c|}
\hline Heurística & Atende & $\begin{array}{c}\text { Não } \\
\text { Atende }\end{array}$ & Observações \\
\hline Visibilidade do status do sistema & $\mathrm{X}$ & & $\begin{array}{l}\text { O sistema indica onde a usuário está } \\
\text { navegando. É possível customizar } \\
\text { mensagens de status. }\end{array}$ \\
\hline Relação entre o sistema e o mundo real & $\mathrm{X}$ & & $\begin{array}{l}\text { Desenvolvido a partir do conceito de } \\
\text { empréstimo de livros facilitando, } \\
\text { inclusive, a interação pessoal entre os } \\
\text { usuários que estão interessados num livro } \\
\text { específico ou em vários livros. }\end{array}$ \\
\hline Controle e liberdade do usuário & $\mathrm{X}$ & & $\begin{array}{l}\text { Cada usuário possui a liberdade de } \\
\text { cadastrar ou excluir seus livros da } \\
\text { Biblioteca Compartilhada. Há } \\
\text { possibilidade de editar e excluí-las em } \\
\text { caso de erros. }\end{array}$ \\
\hline Consistência e padronização & $\mathrm{X}$ & & $\begin{array}{l}\text { Segue o padrão visual do Framework } \\
\text { Bubble. }\end{array}$ \\
\hline Prevenção de erros & $\mathrm{X}$ & & $\begin{array}{l}\text { Os livros são cadastrados inicialmente a } \\
\text { partir da base de dados do Google Books } \\
\text { com possibilidade de edição caso } \\
\text { necessário. } \\
\text { São apresentadas mensagens de } \\
\text { confirmação antes de inclusão ou } \\
\text { exclusão de registros. }\end{array}$ \\
\hline $\begin{array}{l}\text { É mais fácil reconhecer do que ter que } \\
\text { lembrar }\end{array}$ & $\mathrm{X}$ & & $\begin{array}{l}\text { O sistema possui poucas telas e obedece } \\
\text { ao princípio de acessibilidade com no } \\
\text { máximo três cliques. }\end{array}$ \\
\hline Flexibilidade e eficiência no uso & $\mathrm{X}$ & & $\begin{array}{l}\text { O aplicativo atende aos requisitos } \\
\text { planejados de forma simples usando } \\
\text { apenas os recursos necessários. }\end{array}$ \\
\hline Projeto estético e minimalista & $\mathrm{X}$ & & $\begin{array}{l}\text { Interface limpa apresentando apenas } \\
\text { textos essenciais. }\end{array}$ \\
\hline $\begin{array}{l}\text { Ajudar o usuário a reconhecer, } \\
\text { diagnosticar e corrigir erros }\end{array}$ & $\mathrm{X}$ & & $\begin{array}{l}\text { Há recursos para personalização de } \\
\text { mensagens de erro. }\end{array}$ \\
\hline Ajuda e documentação & $\mathrm{X}$ & & $\begin{array}{l}\text { Existe possibilidade de documentação do } \\
\text { sistema bem como ajuda online. }\end{array}$ \\
\hline
\end{tabular}

Fonte: Elaborado pelos autores a partir de Nielsen (1995). 
O resultado da avaliação demonstra que é possível a criação de uma rede social para empréstimos de livros entre usuários com o uso do framework visual Bubble, atendendo aos requisitos operacionais planejados e aos aspectos de usabilidade apontados por Nielsen.

O protótipo do aplicativo BiblioCom se apresentou consistente com a proposta deste estudo e, uma vez desenvolvido e implementado, poderá permitir, além de empréstimo de livros entre os usuários, uma ampliação virtual do acervo de bibliotecas públicas ou privadas que poderiam integrar seus acervos de livros ao BiblioCom e utilizar o aplicativo como mais uma forma de interação com seus usuários.

\section{Considerações finais}

Em um mundo globalizado da sociedade da informação, somos impulsionados pelas Tecnologias da Informação e Comunicação (TIC), num cenário em que a informação e o conhecimento fazem parte de fatores importantes mundialmente, no contexto das redes de informação.

Tanto no campo da biblioteconomia, como em outras áreas do conhecimento humano, as transformações são provenientes das revoluções técnico-científicas que modificam as teorias e práticas específicas de cada campo. Esta pesquisa fundamentou-se no propósito de repensar as formas de interação entre usuário e biblioteca, os serviços que são prestados, e as possibilidades de incrementá-los pelo uso intensivo e objetivo das tecnologias da informação e comunicação, sempre mirando na inovação, e no seu valor para os usuários das unidades de informação.

O protótipo de aplicativo BiblioCom, como proposta deste estudo, pode ser considerado consistente, pois, uma vez desenvolvido e implementado, permitirá, além do empréstimo de livros entre os usuários, uma ampliação virtual do acervo de bibliotecas públicas ou privadas, ou seja, das bibliotecas institucionais.

As bibliotecas podem integrar seus acervos de livros ao BiblioCom e utilizar o aplicativo como mais uma forma de interação com seus usuários, pois o aplicativo por si só, gera uma interação entre as pessoas para um convívio além do virtual.

A rede social BiblioCom implementada para este estudo, permitiu o atendimento dos requisitos planejados para o sistema, sendo o framework Bubble uma ferramenta de 
programação visual em ambiente web por meio da qual possibilita a implementação de aplicativos tanto para desktop como dispositivos móveis, abrangendo celulares, smartphones e tablets.

\section{Referências}

ASSOCIAÇÃO BRASILEIRA DE NORMAS TÉCNICAS. NBR 9241-11: requisitos ergonômicos para trabalho de escritórios com computadores. Parte 11 - orientações sobre Usabilidade. Rio de Janeiro: ABNT, 2002.

BOTSMAN, R; ROGERS, R. O que é meu é seu: como o consumo coletivo está mudando o nosso mundo. Porto Alegre: Bookman, 2011.

CALAZANS, A. T. S. Estudo de caso: uma estratégia de pesquisa. In: MUELLER, S. P. M. (Org.). Métodos para pesquisa em Ciência da Informação. Brasília: Thesaurus, 2007. p. 39-62.

ENTREPENEUR. 2011 trends: it is nice to share. Dec. 2011.

GANSKY, L. MESH: porque o futuro dos negócios é compartilhar. Rio de Janeiro: Alta Books, 2011.

IVAR-SOUZA, F. Redes sociais e os impactos dessa inovação nas organizações: um estudo de caso da rede corporativa "Comunidade de Negócios" da área comercial das empresas do Grupo Algar. Revista Gestão \& Tecnologia, Pedro Leopoldo, v. 14, n. 1, p. 225-244, jan./abr. 2014. Disponível em: <http://revistagt.fpl.edu.br/get/article/view/516>. Acesso em: 08 jun. 2017.

JOHNSON, L. et al. NMC horizon report: 2014 Library edition. Austin: The New Media Consortium, 2014. Disponível em: 〈https://www.nmc.org/pdf/2014-nmc-horizon-report-heEN.pdf> . Acesso em: 21 nov. 2016.

LAKATOS, E. M.; MARCONI, M. A. Técnicas de pesquisa. 5. ed. São Paulo: Atlas, 2002.

LUBISCO, N. M. L. A biblioteca universitária no processo de "avaliação das condições de oferta" dos cursos de graduação pelo MEC: o caso da UFBA. Salvador, 2001. 2v. Dissertação (Mestrado em Ciência da Informação) - Instituto de Ciência da Informação, Universidade Federal da Bahia, 2001. Disponível em:

<http://www.repositorio.ufba.br:8080/ri/bitstream/ri/15087/1/N\%C3\%ADdia\%20Maria\%20L ienert\%20Lubisco.pdf>. Acesso em: 18 mar. 2017.

MACHADO, M.; BLATTMANN, Ú. A biblioteca universitária e sua relação com o projeto pedagógico de um curso de graduação. Biblos: Revista do Instituto de Ciências Humanas e da Informação, Rio Grande, v. 25, n. 1, p. 9-20, jan./jun. 2011. Disponível em: <https://seer.furg.br/biblos/article/view/1993> . Acesso em: 17 mar. 2017. 
MARTELETO, R. M. Análise de redes sociais: aplicação nos estudos de transferência da informação. Ciência da Informação, Brasília, v. 30, n. 1, p. 71-81, jan./abr. 2001.

MENDES, F. S.; CEROY, F. M. Economia compartilhada e a política nacional de mobilidade urbana: uma proposta de marco legal. Brasília: Núcleo de Estudos e Pesquisas/CONLEG/Senado, nov. 2015. (Texto para Discussão, $\mathrm{n}^{\circ}$ 185). Disponível em: <www.senado.leg.br/estudos >. Acesso em: 27 mar. 2017.

NIELSEN, J. 10 usability heuristics for user interface design. Nielsen Norman Group. 1995. Disponível em: <http://www.nngroup.com/articles/ten-usability-heuristics/>. Acesso em: 21 nov. 2016.

Usability 101: introduction to usability. Nielsen Norman Group. 2012. Disponível em: 〈https://www.nngroup.com/articles/usability-101-introduction-to-usability/> . Acesso em: 21 nov. 2016.

Usability engineering. Chestnut Hill: Academic Press, 1993.

PRATES, R. O.; BARBOSA, S. D. J. Avaliação de interfaces de usuários: conceitos e métodos. In: CONGRESSO NACIONAL DA SOCIEDADE BRASILEIRA DE COMPUTAÇÃO, 23., 2003. Anais... Disponível em: <http://www-di.inf.pucrio.br/ simone/files/JAI2003_avaliacao_s.pdf $>$. Acesso em: 08 jun. 2017.

SOARES, C.; VELOSO, A.; MEALHA, Ó. Os desafios de usabilidade nas redes sociais: exemplo prático "Facebook". In: CONGRESSO LUSOCOM - COMUNICAÇÃO, CULTURA E DESENVOLVIMENTO, 10., 2012. Anais... Lisboa: CAPP, 2012. Disponível em: 〈http://www.seduce.pt/SITE_EN/documentos/p10/p10_texto.pdf $>$. Acesso em: 07 jun. 2017.

SOARES, R. O.; HOPPEN, N. Aspectos do uso da internet nos negócios pelas grandes empresas no Brasil: um estudo exploratório baseado em sites web. In: ENCONTRO DA ANPAD, 22., 1998. Anais... Foz do Iguaçu: ANPAD, 1998.

SZKOLAR, D. Social networking for academics and scholars. 21 jun. 2012. Disponível em: $<$ https://ischool.syr.edu/infospace/2012/06/21/social-networking-for-academics-andscholars/>. Acesso em: 21 nov. 2016.

SHNEIDERMAN, B.; PLAISANT, C. Designing the user interface: dtrategies for effective human-computer interaction. 4. ed. Boston: Addison-Wesley Longman, 2004.

TOMAÉL, M. I.; ALCARÁ, A. R.; DI CHIARA, I. G. Das redes sociais à inovação. Ciência da Informação, Brasília, v. 34, n. 2, p. 93-104, maio/ago. 2005. Disponível em: 〈http://www.scielo.br/pdf/ci/v34n2/28559.pdf $>$. Acesso em: 21 nov. 2016.

YIN, R. K. Estudo de caso: planejamento e métodos. 2. ed. Porto Alegre: Bookman, 2001. 